\title{
Dynamic analysis of groundwater discharge and partial-area contribution to Pukemanga Stream, New Zealand
}

\author{
V. J. Bidwell ${ }^{1}$, R. Stenger ${ }^{2}$, and G. F. Barkle ${ }^{3}$ \\ ${ }^{1}$ Lincoln Environmental Research, Lincoln Ventures Ltd, Christchurch, New Zealand \\ ${ }^{2}$ Lincoln Environmental Research, Lincoln Ventures Ltd, Hamilton, New Zealand \\ ${ }^{3}$ Aqualinc Research Ltd, Hamilton, New Zealand
}

Received: 13 July 2007 - Published in Hydrol. Earth Syst. Sci. Discuss.: 30 July 2007

Revised: 29 April 2008 - Accepted: 28 June 2008 - Published: 28 July 2008

\begin{abstract}
The proportion and origin of groundwater contribution to streamflow from agricultural catchments is relevant to estimation of the effects of nitrate leached from the soil on the quality of surface waters. This study addresses the partitioning of streamflow contributions from near-surface runoff and from groundwater, each with different contributing land area, on a steep pastoral hillslope in a humid climate. The 3 ha headwater catchment of the perennial Pukemanga Stream, in the North Island of New Zealand, was instrumented for continuous observation of climatic data, streamflow and groundwater level. The dynamics of groundwater levels and groundwater contribution to streamflow were analysed by means of a one-parameter, eigenvalue-eigenfunction description of a 1-D aquifer model. Model results for seven years of daily data predict that $36-44 \%$ of the topographical catchment contributes groundwater to the stream. The remaining groundwater generated within the catchment contributes to streamflow outside the catchment. Groundwater was calculated to be $58-83 \%$ of observed annual streamflow from the topographical catchment. When the smaller groundwater catchment is taken into account, the groundwater contribution to streamflow is $78-93 \%$ on a unit area basis. Concurrent hourly data for streamflow and groundwater levels at two sites indicate the dynamic behaviour of a local groundwater system. Groundwater flow dynamics that support the perennial nature of this headwater stream are consistent with the size of the groundwater body, porosity of the subsurface material, and hydraulic conductivity derived from partitioning of streamflow contributions.
\end{abstract}

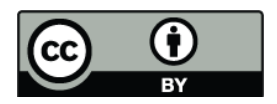

Correspondence to: V. J. Bidwell (bidwellv@lvl.co.nz)

\section{Introduction}

Agricultural land use has long been recognised as a diffuse source of nitrogen, mostly in the form of nitrate, which can cause excessive nutrient levels in surface waters. In New Zealand, pastoral grazing of sheep and beef cattle is considered to be a contributor to issues of undesirable levels of aquatic plant growth in streams and eutrophication of the large freshwater lakes, leading to algal blooms and loss of water clarity (e.g., Smith et al., 1993). Much of the pastoral land use is on hill country, including extensive grazing on steep land. Studies of stream reaches in native forest, exotic pine, and pasture in the steep hills of the Hakarimata Ranges of Waikato Region (Quinn et al., 1997) showed a five-fold difference in nitrate concentrations between pastoral and forest catchments of up to $2 \mathrm{~km}^{2}$. Further studies on catchments up to $3 \mathrm{~km}^{2}$ of the mass export of nutrients during a twoyear period (Quinn and Stroud, 2002) again demonstrated the significantly higher nitrate concentrations in drainage from these pastoral catchments, which can be up to 10 times the recommended threshold $\left(\sim 0.1 \mathrm{~g} \mathrm{~L}^{-1}\right)$ for aquatic water quality. In contrast to this result, the export of dissolved reactive phosphorus was not significantly different between pasture and native forest. The 3 ha Pukemanga Catchment, which is the subject of the present study, is located in the Hakarimata Ranges.

Nitrate from a catchment, as a diffuse effect of agricultural land use, is generated primarily within the soil profile. It is exported from a catchment by water that has passed through the microbially active soil profile. The possible transport routes are through the remainder of the vadose zone to groundwater and hence to the stream, or from the vadose zone to re-emerge at the ground surface as a contribution to

Published by Copernicus Publications on behalf of the European Geosciences Union. 
overland flow. The latter flow process usually depends on temporary saturation within subsurface layers of contrasting hydraulic conductivity. It is our hypothesis that, excluding denitrification processes, the groundwater route is the dominant pathway for nitrate transport, even for small, steep, hillcountry catchments. Validation of this hypothesis is relevant for estimation of nitrate transport times within a catchment, because proposed land use changes for amelioration of nitrate effects on surface waters should take account of the likely response dynamics.

Stewart et al. (2007) conducted a hydrometric and natural tracer study of groundwater contribution to the Pukemanga Stream, for which the primary motivation was the controversy surrounding the nature of subsurface flow in steep to moderate terrain. These authors report that lateral flow in groundwater perched on low conductivity barriers, such as the soil-bedrock interface, was a common process assumption. Their results for tracer residence times indicate that larger bodies of subsurface water than are accounted for by near-surface processes are involved in solute transport in this catchment. The present authors were aware that the Stewart et al. (2007) hypothesis was quite novel for scientists involved in hydrological research on the small, steep, catchments in the hill country of New Zealand. It is our opinion that concepts of shallow, near-surface, groundwater had influenced investigations of solute transport in New Zealand (unpublished reports), and that resolution of the subsurface transport process was necessary for appropriate management of the issue of nitrate from agricultural land use.

One of the complicating factors in conducting hydrometric analyses of a catchment is that the catchment area for groundwater commonly does not coincide with the topographical catchment and groundwater divides may vary with time (Winter et al., 2003). Verry (2003) reports an analysis of 32 small research watersheds, which shows that the groundwater discharge determined from topographical boundaries and not recorded at the streamflow gauge is, on average, about $45 \%$ of the recorded streamflow. Stewart et al. (2007) calculated a water balance for the 3 ha headwater catchment of Pukemanga Stream, which indicated that only $50 \%$ of the drainage from the topographical catchment area actually contributes to streamflow at the flow gauge site and that the remainder is groundwater flow that bypasses the flow gauge site.

The objective of our research was to refine the hydrometric analysis in terms of the dynamics of groundwater flow because the results were likely to provide information about the feasible range of aquifer properties for specified scales of groundwater bodies. These results could be compared with the volumes of groundwater suggested by Stewart et al. (2007) on the basis of groundwater age using natural isotope tracers. The corresponding dynamic behaviour of piezometric data would also be examined to obtain confirmation that deep groundwater was involved in streamflow generation.
The conceptual approach to hydrometric analysis described in the present paper is based on two principles. Firstly, the dynamic response of groundwater discharge to recharge from soil-water drainage can be differentiated from that due to streamflow from near surface processes such as overland flow and lateral subsurface flow. This separation of responses relies on the dynamic structure of groundwater discharge being specified from a theoretical basis. Secondly, the catchment area of groundwater contribution is treated as an unknown to be determined, whereas the near-surface contribution is assumed to originate from the topographical catchment.

The first principle is similar to the long-studied problem of baseflow separation, for which there are many proposed approaches, including those that preserve mass balance within the catchment and employ analytical solutions of simplified groundwater concepts (e.g., Furey and Gupta, 2001; Huyck et al., 2005). These models are typically based on the Boussinesq equation of one dimensional groundwater flow, but can include a parameter for divergence or convergence of flow (Huyck et al., 2005). For the purposes of our research we used the analytical solution of the linearised Boussinesq equation for an aquifer discharging to a fully penetrating stream, similar to an application by Sloan (2000). The additional assumption of time-invariant transmissivity enables this model to be represented in terms of one parameter, which is itself the ratio of lumped aquifer properties and scale. This ratio can then be explored for ranges of feasible values of contributing physical properties.

\section{Methods}

\subsection{Catchment description}

The Pukemanga stream discharges from a small $\left(60 \mathrm{~m}^{2}\right)$ spring-fed wetland on the NW face of a spur (Fig. 1) in the hill country of the Hakarimata Ranges near the west coast of the North Island of New Zealand (37.787 $\left.{ }^{\circ} \mathrm{S}, 175.068^{\circ} \mathrm{E}\right)$ and discharges into the Kiripaka Stream. All of the 3 ha Pukemanga Catchment above the wetland is in pasture, with some poplar trees for erosion control. Land slope is typically about $35^{\circ}$, up to $60^{\circ}$ on gully sideslopes. The land use of this area is pastoral grazing for sheep and beef cattle. The spur lies along a true bearing of $30^{\circ}$ between two streams that meet at a confluence about $1 \mathrm{~km}$ from the wetland. On a cross-section through the spur at the wetland, the distance between the bounding streams is about $430 \mathrm{~m}$, and the ground elevation ranges from about $70 \mathrm{~m}$ amsl at the streams to about $150 \mathrm{~m}$ amsl on the top of the spur. These dimensions are relevant to consideration of the likely groundwater systems in this locality. Figure 1 shows ground elevations along a transect of the main channel of the Pukemanga Catchment and the locations of monitoring devices. A $1050 \mathrm{~m}^{2}$ sub-area of the catchment was the subject of experimental studies of 
runoff processes under a large rainfall simulator (Adams et al., 2005; Adams and Elliott, 2006; Müller et al., 2006).

The geological description of this area (Kear and Schofield, 1978) indicates that the spur lies along the strike of the boundary between the tilted Marokopa Formation and the older Hakarimata Formation (Hokonui System) on the western side of the Hakarimata Anticline. The Pukemanga Catchment appears to lie within the Marokopa Formation. The lithology of these formations near this boundary is described as interbedded fine sandstone and siltstone, with some fossilised shellbeds. The sandstone and siltstone are indurated, those of the Hakarimata are described as well jointed, and these rocks are deeply weathered.

Yellow Ultic Soils and Orthic Granular Soils dominate the catchment. While differing in their parent materials, both groups have clay-enriched B horizons in common that typically result in imperfect drainage (Bruce, 1978; Hewitt, 1998). Mottled Yellow Ultic Soils with silt loam texture in the A-horizon and loamy clay or silty clay below were described at four soil pit sites within the rainfall simulator area (Müller et al., 2006). The A-horizon is characterised by a high organic organic carbon content of 15-20\%, a high total porosity and high macroporosity. The geometric means of the saturated vertical hydraulic conductivity decreased from $36-105 \mathrm{~mm} \mathrm{~h}^{-1}$ at $10 \mathrm{~cm}$ depth to $6-29 \mathrm{~mm} \mathrm{~h}^{-1}$ at $80 \mathrm{~cm}$. Values of 2-12 $\mathrm{mm} \mathrm{h}^{-1}$ were reported for the two sites where samples were additionally taken at $120 \mathrm{~cm}$ depth. The plantavailable water fraction (field capacity - permanent wilting point) varies from $25-28 \%$ at $10 \mathrm{~cm}$ to $12-14 \%$ at $25 \mathrm{~cm}$ (Müller et al., 2006; Table 1). On the basis of these data we estimated the available water capacity (AWC) to be $80 \mathrm{~mm}$ for pasture with root depth of $50 \mathrm{~cm}$.

\subsection{Instrumentation}

Rainfall data were supplied by AgResearch Ltd, which operates the Whatawhata Research Station on which Pukemanga Catchment is located. Streamflow was monitored in two structures, H-flume for high flows (above $6.35 \mathrm{~L} \mathrm{~s}^{-1}$ ) and $\mathrm{V}$-notch weir for low flows. Resolution was $1 \mathrm{~mm}$ for stage and 5-min time interval.

The "deep well" with a casing diameter of $50 \mathrm{~mm}$ and $30 \mathrm{~m}$ depth was installed in March 2004 by commercial well drillers (Brown Bros. (NZ) Ltd., Hamilton). The bore log describes clay down to $9 \mathrm{~m}$ depth, and clay and weathered rock, which became hard at $27 \mathrm{~m}$ below ground surface. The screen extends $27-30 \mathrm{~m}$ below ground surface. The water level in this well was recorded in 15 min resolution using a pressure sensor with integrated data logger (DIVER by Van Essen Instruments).

Shallow well WW4 with a casing diameter of $28 \mathrm{~mm}$ and $5.1 \mathrm{~m}$ depth was installed near the wetland in June 2003 using a direct push-probe system (Geonor, Norway). The installation procedure involved driving a $25 \mathrm{~mm}$ probe down to the required depth using a percussion hammer, followed
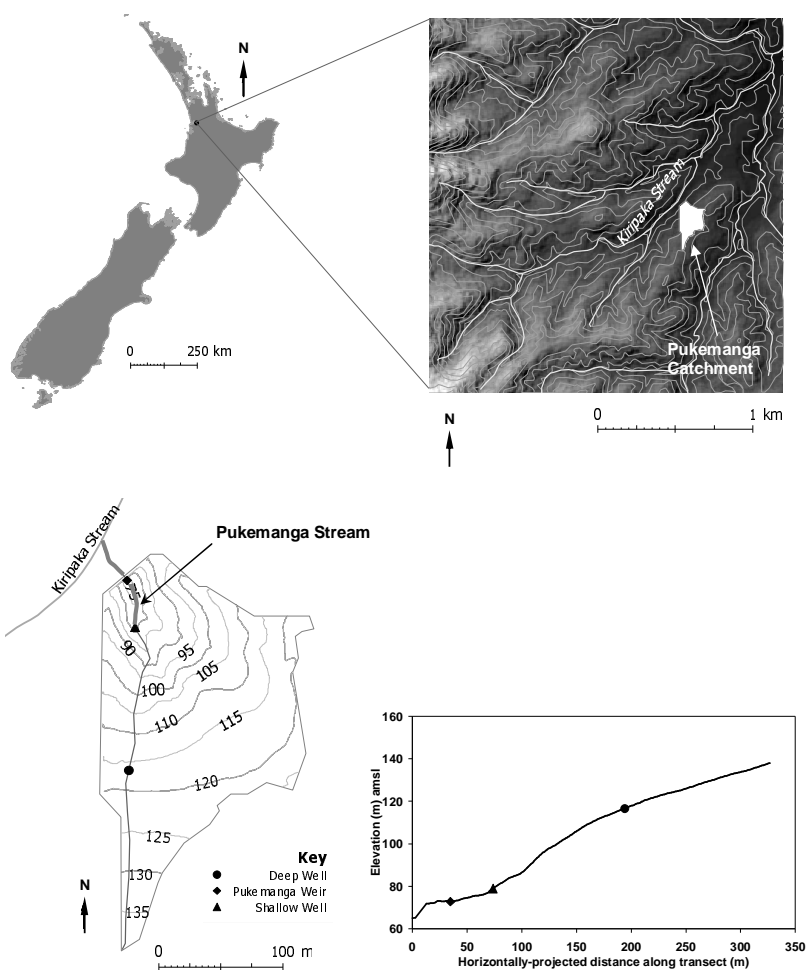

Fig. 1. Pukemanga Catchment, New Zealand, showing location of monitoring sites and transect of ground surface elevation.

by widening of the borehole using an auger. This well is screened from 3.7 to $5.1 \mathrm{~m}$ below ground surface. The water level was recorded in 15 min resolution using a capacitance probe with integrated data logger (WT-HR Water Height Data Logger by TruTrack, Christchurch, NZ).

\subsection{Data}

Rainfall, streamflow, and ground elevation data were provided by the National Institute of Water and Atmospheric Research (NIWA). Values of potential evapo-transpiration (PET) were calculated from climatic data following FAO-56 (Allen et al., 1988). The datasets used for the following analyses were:

- Daily rainfall, PET, and Pukemanga streamflow for the period 9/8/1995 to $18 / 1 / 2003$. The calendar years 1996 to 2002 were used for model calibration. Only the years 1996, 1999, 2000, and 2002 had complete streamflow records and these were also used for checking annual water balance.

- Hourly rainfall, PET, and Pukemanga streamflow for the periods $1 / 4 / 1998$ to $31 / 3 / 1999$ and $1 / 1 / 2004$ to $29 / 11 / 2005$. Several gaps in the streamflow record for the latter period, each of no more than four hours duration, were filled by linear interpolation within the record. 
Table 1. Hydrometric model parameters for daily data from Pukemanga 1996-2002.

\begin{tabular}{|c|c|c|c|c|c|c|c|c|c|c|}
\hline a & Parameter & 1996 & 1997 & 1998 & $\begin{array}{c}\text { Year } \\
1999\end{array}$ & 2000 & 2001 & 2002 & Mean & SSE \% \\
\hline \multirow{4}{*}{ 1. to 3 . } & $\alpha\left(\mathrm{d}^{-1}\right)$ & & & & 0.0085 & & & & & \multirow{4}{*}{100} \\
\hline & $T_{v}(\mathrm{~d})$ & & & & 1.00 & & & & & \\
\hline & $A_{g w}(\mathrm{ha})$ & & & & 1.13 & & & & & \\
\hline & $D_{T}\left(\mathrm{~mm} \mathrm{~d}^{-1}\right)$ & & & & 21.0 & & & & & \\
\hline \multirow{4}{*}{4.} & $\alpha\left(\mathrm{d}^{-1}\right) \times 10^{-3}$ & 11.7 & 8.1 & 8.1 & 7.0 & 5.9 & 6.1 & 12.3 & 8.5 & \multirow{4}{*}{88} \\
\hline & $T_{v}(\mathrm{~d})$ & 1.00 & 1.00 & 1.00 & 1.00 & 1.00 & 1.00 & 1.00 & 1.00 & \\
\hline & $A_{g w}(\mathrm{ha})$ & 1.32 & 1.14 & 1.16 & 1.09 & 1.15 & 1.32 & 1.14 & 1.19 & \\
\hline & $D_{T}\left(\mathrm{~mm} \mathrm{~d}^{-1}\right)$ & 21.0 & 21.0 & 21.0 & 21.0 & 21.0 & 21.0 & 21.0 & 21.0 & \\
\hline 5. & $A_{g w}(\mathrm{ha})$ & 1.32 & 1.13 & 1.16 & 1.06 & 1.10 & 1.29 & 1.14 & 1.17 & 94 \\
\hline
\end{tabular}

a Refers to a step in the "Analytical procedure" section.

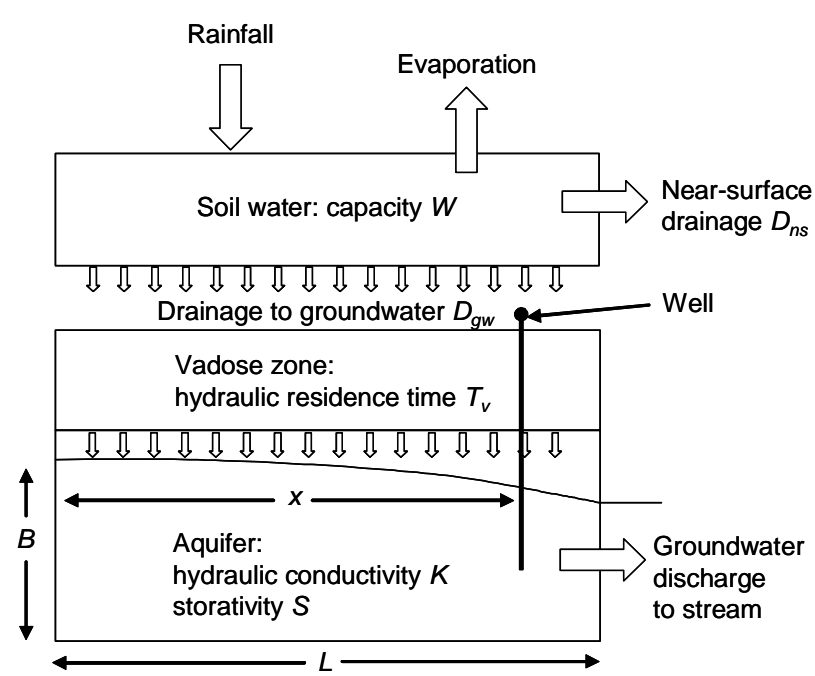

Fig. 2. Hydrometric model used for prediction of groundwater discharge and water balance analysis.

- Hourly groundwater level in the deep well, for the period $15 / 5 / 2004$ to $27 / 10 / 2005$. There are some missing data caused by groundwater levels exceeding the measurement range of the instrument. The period $16 / 7 / 2004$ to $27 / 10 / 2005$ was used for calibration.

- Hourly groundwater level for shallow well WW4. There are missing data caused by instrument failure. The period 1/5/2004 to 27/10/2005 was used for calibration.

\subsection{Hydrometric dynamic model}

The hydrometric model (Fig. 2) comprises the following components:

A soil-water balance model that generates drainage $D(k)$ in the $k$ th time period when the soil-water capacity $W$ is exceeded by the net effect of precipitation inflow $R(k)$ and evaporation outflow $E(k)$. Evaporation $E(k)$ is calculated from Penman values of potential evaporation $P(k)$, a constant crop factor $C$ and a reduction function $F[s, w(k)]$ (Minhas et al., 1974) sensitive to soil water content at the beginning of the period, $S(k-1)$, expressed as a fraction $w(k)$ of $W$.

$$
\begin{aligned}
& w(k)=\frac{S(k-1)}{W} \\
& E(k)=C \times F[s, w(k)] \times P(k) \\
& F(s, w)=\frac{1-\exp (-s w)}{1-2 \exp (-s)+\exp (-s w)} \\
& S(k)=\min [R(k)+S(k-1)-E(k), W] \\
& D(k)=\max [R(k)+S(k-1)-E(k)-W, 0]
\end{aligned}
$$

The evaporation reduction function $F(s, w)$ has a range of $0-1$, and the parameter $s$ controls the shape of the reduction curve as the soil-water content fraction $w$ varies from zero to one. After some initial testing for sensitivity of model results to variations in $s$, a value of $s=10$ was used for all analyses. This results, approximately, in values of $F(10, w)=1.0$ for $w=0.4$ to 1.0 , with smooth transition to a linear variation between $F(10,0)=0$ and $F(10,0.2)=0.8$.

Drainage $D(k)$ is partitioned into drainage entering groundwater $D_{g w}(k)$ and near-surface drainage $D_{n s}(k)$, by means of a drainage threshold value $D_{T}$ for the respective time period, so that:

$$
\begin{aligned}
& D_{g w}(k)=\min \left[D(k), D_{T}\right] \\
& D_{n s}(k)=\max \left[D(k)-D_{T}, 0\right]
\end{aligned}
$$

These two drainage components, $D_{g w}(k)$ and $D_{n s}(k)$, were calculated on a unit area basis $\left(\mathrm{mm} \mathrm{d}^{-1}\right.$ or $\left.\mathrm{mm} \mathrm{h}^{-1}\right)$. These values were then converted to two contributions to streamflow $\left(\mathrm{L} \mathrm{s}^{-1}\right)$ by use of two catchment areas: the area $A_{g w}$ 
contributing to groundwater discharge, which was allowed to vary as a model parameter; and area $A_{n s}$ contributing to near surface drainage, which was set equal to the topographical catchment area of 3.0 ha.

The dynamics of vertical water transport through the vadose zone to the groundwater surface is represented by a single, first-order storage (e.g., Bidwell, 2005) with a mean storage time $T_{v}$.

The groundwater component is represented as a 2-D vertical slice of a homogeneous aquifer receiving spatiallyuniform recharge on the top surface. One end of the aquifer is considered to be at the groundwater divide, with a no-flow boundary condition, and groundwater discharges from the other end (Fig. 2). The responses of groundwater discharge and groundwater level to recharge are expressed in terms of the eigenvalue solution to aquifer dynamics (Sahuquillo, 1983). For the simple case in Figure 2, the analytical solution (Sloan, 2000; Pulido-Velazquez et al., 2005) is a function of only one parameter $\alpha$, which is determined by aquifer length $L$, storativity $S$ and transmissivity $T$. The full mathematical description of this groundwater component is given in Appendix A. In this paper we resolve transmissivity $T$ into aquifer thickness $B$ and hydraulic conductivity $K$, for the purpose of considering feasible aquifer dimensions and properties.

$\alpha=\frac{K B}{S L^{2}}$

Appendix A describes how the dynamics of the vadose zone and aquifer system can be mathematically represented by the set of difference equations:

$$
\begin{aligned}
y_{i}(k) & =\left(a_{i}+a_{v}\right) y_{i}(k-1)-a_{i} a_{v} y_{i}(k-2) \\
& +b_{i} b_{v} D_{g w}(k) \\
y(k) & =\sum_{i=0}^{n} y_{i}(k)
\end{aligned}
$$

which relate groundwater discharge or piezometric head, as $y(k)$, to the drainage component $D_{g w}(k)$. The coefficients of Eq. (4) are functions (Appendix A) of the vadose zone hydrometric storage time $T_{v}$ and the aquifer property parameter $\alpha$. The first ten $(n=10)$ eigenvalues of the aquifer model solution were used for this application. Thus the hydrometric model of groundwater discharge has four parameters to be calibrated from climate and streamflow data: groundwater catchment area $A_{g w}$; value of soil water drainage $D_{T}$ that determines partitioning between recharge to groundwater and near-surface flow; hydrometric residence time $T_{v}$ of the vadose zone; and the dynamic parameter $\alpha$ of groundwater discharge.

The hydrometric model was implemented in Excel spreadsheet and the "Solver" tool used for model calibration. The primary objective function for calibration of the hydrometric model was minimisation of the sum of squared errors (SSE streamflow) for streamflow predictions up to $1.0 \mathrm{~L} \mathrm{~s}^{-1}$. This range of flows includes $93 \%$ of all daily average streamflow and was selected to avoid the influence on model calibration of shorter-duration daily average flow events in the range of 1.0 to $12 \mathrm{~L} \mathrm{~s}^{-1}$. Unpublished $\mathrm{SiO}_{2}$ data (G. F. Barkle, personal communocation) also indicates that the "old water" contribution to Pukemanga streamflow occurs at this low flow range. A secondary objective function was the sum of squared annual water balance errors (SSE water balance) for the four years of complete daily data.

The eigenvalue approach represents the aquifer as a parallel set of linear water storages, which is in series with the vadose zone storage. Therefore the system state in terms of water content is easily calculated, which enables water balance calculations over any time period to take account of changes in the water storage status of the vadose zone and the aquifer.

\subsection{Groundwater level response of the hydrometric model}

The response of groundwater level $h(x, t)$ in the aquifer component of the hydrometric model to recharge (piezometric response) involves coefficients that depend on the aquifer storativity $S$ and the ratio $x / L$, where $x$ is the distance from the no-flow boundary or groundwater divide (Fig. 2). The full mathematical description is given in Appendix A, Eq. (A6). The piezometric level $h(x, t)$ is relative to a datum $d$ that corresponds to zero groundwater discharge from the aquifer. Usually, $d$ is not known and is therefore a model parameter.

\subsection{Model calibration procedure}

The aim of the model calibration procedure was to best use the available climate, streamflow, and piezometric data, which are at daily and hourly timescales, have some missing data record, and have only partial overlapping periods. The dynamic parameter $\alpha\left[\mathrm{T}^{-1}\right]$, defined by Eq. (1), was recognised as the common element (pro-rated for time scale) for the hydrometric model at both time scales as well as for the piezometric response at houry scale. The value of $\alpha$ defines groundwater dynamics and hence the change in groundwater storage in response to infiltrating recharge $D_{g w}(k)$ from the groundwater catchment area $A_{g w}$. These parameters account for changes in stored water when calibrating to annual water balances. Vadose zone residence time $T_{v}$ has a negligible effect on water balance but can improve the fit to streamflow data. The following calibration steps address model fit firstly to daily hydrometric data, then to hourly hydrometric data, and finally to hourly piezometric data.

1. The hydrometric model was fitted to the 1996-2002 daily streamflow data by calibrating the values of groundwater catchment area $A_{g w}$, drainage threshold $D_{T}$, dynamic parameter $\alpha$, and vadose zone residence time $T_{v}$, to minimise SSE (streamflow). 


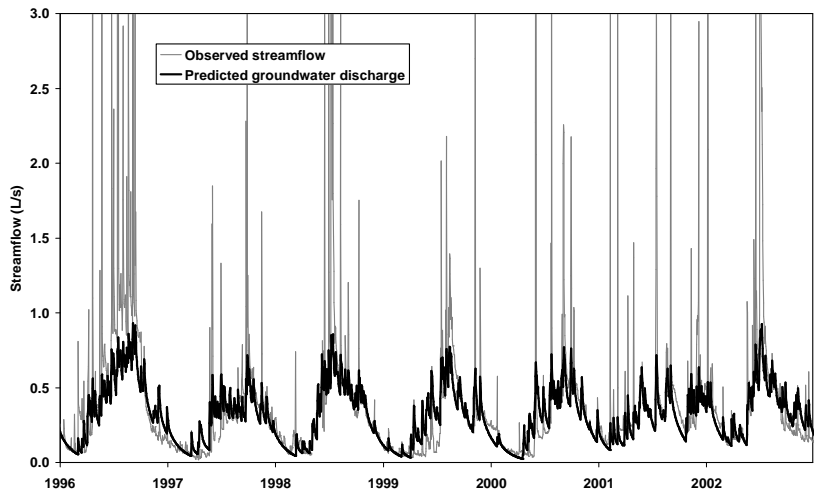

Fig. 3. Predicted daily groundwater discharge to Pukemanga Stream, for parameter set \#1 in Table 1.

2. The values of $A_{g w}$ and $D_{T}$ were then recalibrated to minimise the SSE (water balance) for the four years 1996, 1999, 2000, 2002. The previous values of $\alpha$ and $T_{v}$ were sufficient for calculation of the changes in stored water for each year.

3. With $A_{g w}$ and $D_{T}$ held at the values from 2., the parameters $\alpha$ and $T_{v}$ were recalibrated to minimise the SSE (streamflow) for the seven years 1996-2002.

4. As a test of robustness, the four model parameters were fitted to each of the seven years, minimising SSE (streamflow), using initial values from 3 .

5. Since the value of $D_{T}$ remained stable in 4. $A_{g w}$ was calibrated with the other parameters held at the values determined in 3 .

6. Water balance errors for each of the years 1996, 1999, 2000, 2002 were calculated for three cases of assumptions about groundwater catchment area $A_{g w}:$ (1) $A_{g w}=3.0 \mathrm{ha}$; (2) $A_{g w}$ has the same value for all years; (3) $A_{g w}$ varies from year to year.

7. The contribution of predicted groundwater discharge as a percentage of predicted total drainage was calculated from the seven years of daily data for two cases: on a unit area basis $\left(\mathrm{mm} \mathrm{y}^{-1}\right)$ and on a weighted area basis that accounts for the different catchment areas for nearsurface runoff and groundwater discharge.

8. The hydrometric model was fitted to hourly data for $1 / 4 / 1998-31 / 3 / 1999$ by scaling $\alpha$ from a daily rate to an hourly rate, assigning $A_{g w}$ to the 1998 value from the daily model, and then calibrating the parameters $D_{T}$ and $T_{v}$.

9. The hydrometric model was then calibrated to the hourly data for $1 / 1 / 2004-30 / 9 / 2005$ by fitting only the groundwater catchment area $A_{g w}$.
10. The groundwater level data for the deep well were calibrated to the piezometric response of the hydrometric model by fitting the values of storativity $S$, location ratio $x / L$, and datum $d$, with all other parameters retained at the previously calibrated values.

11. The groundwater level data for the shallow well WW4 were calibrated to the piezometric response model by retaining the value of storativity $S$ from the deep well and fitting only the values of location ratio $x / L$ and datum $d$.

12. A table of values of hydraulic conductivity was calculated from Eq. (3) for consideration of feasible aquifer dimensions corresponding to the derived value of the dynamic parameter $\alpha$.

\section{Results and Discussion}

\subsection{Groundwater catchment area and water balance}

Table 1 shows the values of the four parameters of the hydrometric model, calibrated with daily data, for each of the three cases: same values for all years; different values for each year; and only contributing groundwater catchment area allowed to vary with each year.

Figure 3 shows the seven years of predicted daily groundwater flow, compared with the record of observed daily streamflow, for the parameter values shown in Table 1 for analytical steps 1 to 3 .

The dynamic behaviour of low flow in the catchment, especially during periods of negligible soil drainage, is defined by the calibrated value of the parameter $\alpha=0.0085 \mathrm{~d}^{-1}$ that is used in the groundwater component of the hydrometric model (Fig. 2). The dynamic contribution of transport through the vadose zone is very small, as quantified by the mean hydraulic residence time of $T_{v}=1.0 \mathrm{~d}$ (Table 1, \#3). Only two other parameters of the hydrometric model are involved in matching estimated soil-water drainage to observations of low streamflow that is hypothesised to be groundwater discharge. These are: catchment area contributing to groundwater, $A_{g w}$; and the threshold vertical drainage rate, $D_{T}$, which partitions total soil drainage into groundwater recharge and near-surface drainage. There is potential for interdependence between these two parameters because their product defines the amount of groundwater recharge from the time series of estimated total soil-water drainage. Table 1 (\#4) shows the effect of calibrating the four model parameters to each year of annual data. The aquifer dynamic parameter $\alpha$ does vary considerably, and this may indicate that the simple aquifer component of the hydrometric model does not capture the full range of low flow behaviour. The vadose zone dynamic parameter $T_{v}$ is quite robust, as might be expected, but the lack of variation in the drainage threshold of $D_{T}=21.0 \mathrm{~mm} \mathrm{~d}^{-1}$ is more surprising. Given this fixed value 
of $D_{T}$, it is expected that groundwater catchment area $A_{g w}$ would vary so that water balance errors are minimised.

Allowing all model parameters to vary annually reduced the objective function, SSE (streamflow), to $88 \%$ of its value for parameters that are the same for all years. However, since there is not a sound physical reason for allowing the dynamic parameter $\alpha$ to vary, this variation was recognised as a statistical feature of the model concept, and the calibrated value for the seven years data was retained. However, there is a physical basis for temporal variation of the groundwater catchment area $A_{g w}$. Winter et al. (2003) present three examples of sites in Nebraska, North Dakota and Germany where groundwater divides vary in response to time variation of the recharging precipitiation. Therefore, the value of groundwater catchment area $A_{g w}$ was recalibrated for each year with the other three model parameters held constant (Table 1, \#5). The resulting SSE (streamflow) was $94 \%$ of the constant area case. The values of $A_{g w}=1.09-1.32$ ha are significantly smaller ( $36 \%$ to $44 \%$ ) than the topographical catchment area of 3.0 ha.

Table 2 shows the annual water balance predictions and errors for the four years with complete daily streamflow records. The results are for three assumptions about the contributing groundwater catchment area $A_{g w}$ : equal to the 3.0 ha topographical catchment area; fixed calibrated value for all seven years; and calibrated value can vary in each of the seven years.

The use of the topographical catchment area of 3.0 ha for water balance calculations leads to gross errors of 84 to $189 \%$ overestimation of streamflow, whereas either of the results from assumptions about a smaller area of contributing groundwater reduces this error to a range of -16 to $+33 \%$. The case for time-varying groundwater catchment area does not improve the average water balance error for the four years. The calibration requirement for fitting daily groundwater discharge with the single parameter $(\alpha)$ groundwater model had the effect of constraining other model parameters to values that preclude alternative explanation of the water balance simply in terms of uncertainty in climate data or water partitioning at the land surface.

\subsection{Contribution of groundwater discharge to streamflow}

Table 3 shows the predicted groundwater contribution for each of the seven years of daily data, as a percentage of the total predicted streamflow. Two measures are used, "Unit area" and "Weighted", which reflect the influence of the groundwater catchment area not being the same as the topographical area that is assumed to control near-surface runoff:

"Unit area" $=\frac{D_{g w}}{D_{g w}+D_{n s}} \quad$ "Weighted" $=\frac{A_{g w} D_{g w}}{A_{g w} D_{g w}+A_{n s} D_{n s}}$

Two assumptions are considered about groundwater catchment area: fixed for all years at the calibrated value; and calibrated area can vary from year to year.

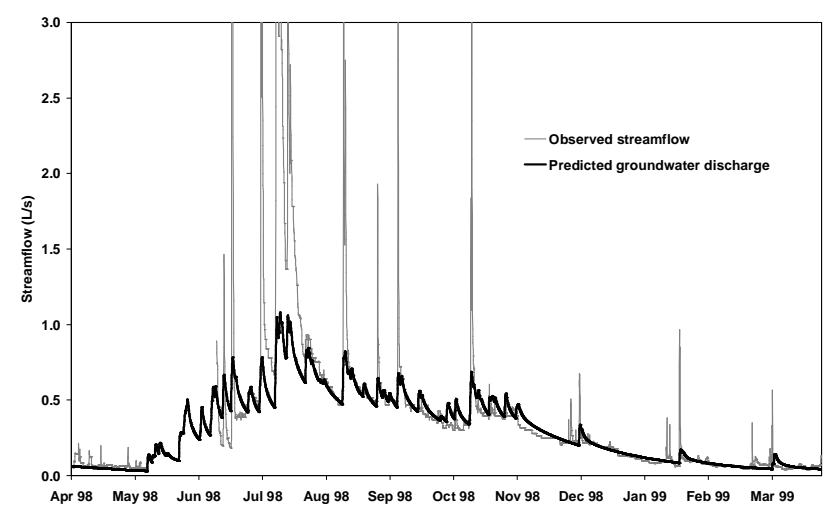

Fig. 4. Predicted hourly groundwater discharge for Pukemanga Stream, 1/4/1998-31/3/1999.

The proportion of groundwater contribution to streamflow is relevant to estimation of nitrate loads from catchments because of the assumption that most nitrate leached from the soil profile is transported by soil-water drainage that becomes recharge to the underlying groundwater. A small amount of nitrate may also be transported by soilwater drainage that is involved in near-surface contribution to streamflow but this can usually be neglected in calculations if the proportion of near-surface flow processes is also small. The groundwater contribution to a particular stream gauging location can be different from the topographical catchment area. This difference raises the question of how to report the partitioning of catchment drainage flowpaths: either as unit land area hydrological processes ("unit area"); or weighted according to groundwater catchment area and topographical catchment area ("weighted"). The respective modelled groundwater contributions for these two bases ("unit area" and "weighted") for each of the seven years of daily data are shown in Table 3. For the two modelling assumptions about groundwater catchment area (Table 3), the timeaveraged groundwater contribution is $78-93 \%$ on a unit area basis and $58-83 \%$ on an annual streamflow basis, specifically for Pukemanga.

\subsection{Dynamic linkages}

Table 4 shows how calibration of the hourly models of streamflow and piezometric response of wells proceeded within constraints set by prior results obtained in earlier stages. Thus the dynamic parameter $\alpha$ is carried through from the daily models, and annually varying groundwater catchment area $A_{g w}$ has a common value for the one year (1998) of daily and hourly data. Figures 4 and 5 show the hourly predictions of groundwater flow, and Figs. 6 and 7 show the predicted hourly piezometric response at the deep and shallow monitoring wells. 
Table 2. Annual water balance components and errors for daily data from Pukemanga.

\begin{tabular}{lrrrrr}
\hline Year & 1996 & 1999 & 2000 & 2002 & Mean \\
\hline Rainfall $R(\mathrm{~mm})$ & 1967 & 1532 & 1565 & 1678 & 1685 \\
Potential evaporation $P(\mathrm{~mm})$ & 832 & 807 & 775 & 783 & 799 \\
Predicted evaporation $E(\mathrm{~mm})$ & 642 & 595 & 596 & 625 & 615 \\
Predicted groundwater recharge (mm) & 1128 & 829 & 794 & 950 & 1002 \\
Predicted near-surface runoff $(\mathrm{mm})$ & 181 & 117 & 122 & 125 & 136 \\
Observed mean streamflow $\left(\mathrm{L} \mathrm{s}^{-1}\right)$ & 0.660 & 0.308 & 0.332 & 0.474 & 0.444 \\
Predicted mean streamflow $\left(\mathrm{L} \mathrm{s}^{-1}\right)$ for: & & & & & \\
$A_{g w}=3.0$ ha & 1.217 & 0.890 & 0.809 & 1.092 & 0.986 \\
Error (\%) & 84 & 189 & 144 & 130 & \\
$A_{g w}=1.13$ ha for all years & $\mathrm{a}$ \\
Error $(\%)$ & 0.556 & 0.410 & 0.345 & 0.498 & 0.452 \\
$A_{g w}$ varies from year to year & -16 & 33 & 4 & 5 & \\
Error $(\%)$ & 0.623 & 0.393 & 0.338 & 0.502 & 0.464 \\
& -6 & 28 & 2 & 6 & \\
\hline
\end{tabular}

a \#3 in Table 1.

$\mathrm{b} \# 5$ in Table 1.
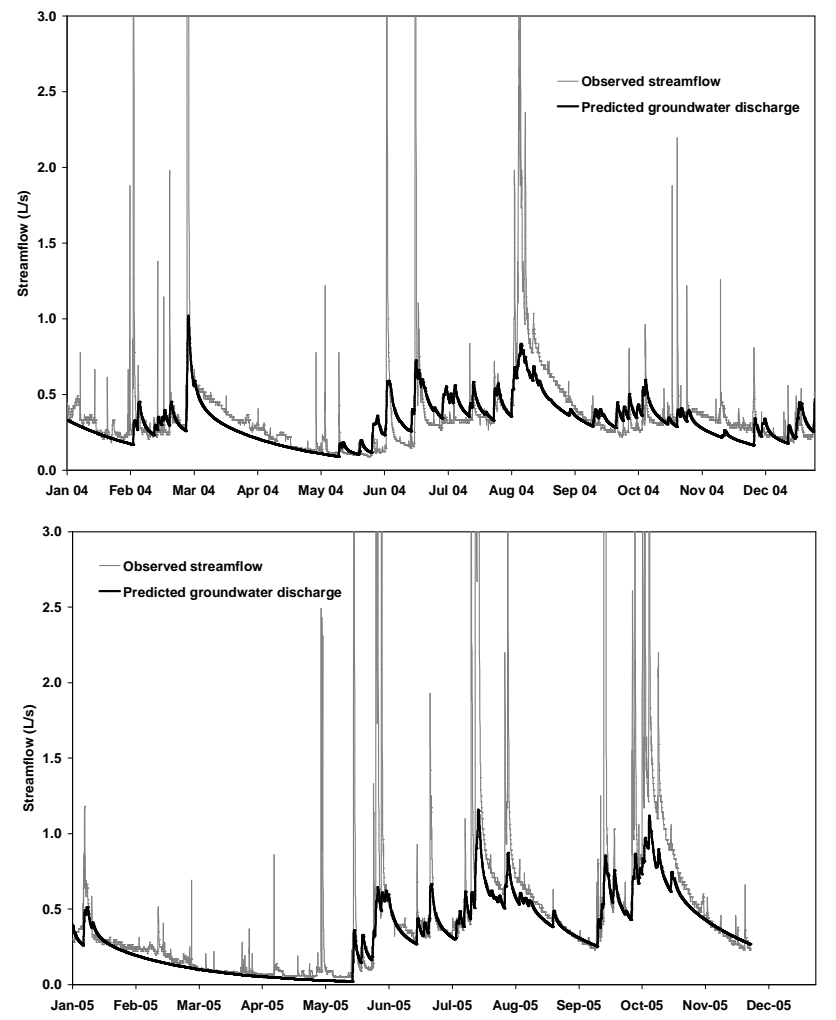

Fig. 5. Predicted hourly groundwater discharge for Pukemanga Stream, 2004-2005.
Table 3. Predicted groundwater discharge as a percent of predicted total drainage.

\begin{tabular}{ccccc}
\hline & \multicolumn{2}{c}{$A_{g w}=1.13 ; D_{T}=21.0^{\mathrm{a}}$} & \multicolumn{2}{c}{$A_{g w}$ variable; $D_{T}=21.0^{\mathrm{b}}$} \\
\hline & Unit area & Weighted & Unit area & Weighted \\
\hline 1996 & 86 & 70 & 86 & 73 \\
1997 & 93 & 83 & 93 & 83 \\
1998 & 78 & 58 & 78 & 58 \\
1999 & 88 & 73 & 88 & 72 \\
2000 & 87 & 71 & 87 & 71 \\
2001 & 81 & 61 & 81 & 64 \\
2002 & 88 & 74 & 88 & 74 \\
Mean & 86 & 70 & 86 & 71 \\
\hline
\end{tabular}

a \#3 in Table 1.

$\mathrm{b} \# 5$ in Table 1.

The groundwater derived from the non-contributing area within the topographical catchment, and hence not measured at the streamflow gauge, is usually termed "deep seepage" as a water balance item. However, we are concerned about the origin and fate of this unaccounted groundwater flow because of its role in transport of nitrate from land use origin to its contribution to surface water quality. This requires an approach that takes into account the regional groundwater system at a larger scale, within which the contribution to Pukemanga Stream is a local groundwater system (e.g., Winter et al., 2003). The dynamic behaviour of this local system is quantified by the parameter $\alpha$ (Eq. 3) of the hydrometric model. The value of $\alpha=0.0085 \mathrm{~d}^{-1}$ from the daily model was pro-rated to $\alpha=0.00035 \mathrm{~h}^{-1}$ for use in an hourly version of the model. Calibration of this hourly model during the 1998-1999 period concurrent with 
Table 4. Hydrometric and piezometric model parameters for hourly data.

\begin{tabular}{lcccc}
\hline \multirow{2}{*}{ Parameter } & \multicolumn{2}{c}{ Hydrometric model } & \multicolumn{2}{c}{ Piezometric model } \\
& $1 / 4 / 1998-31 / 3 / 1999$ & $1 / 1 / 2004-29 / 11 / 2005$ & Deep well & Shallow well \\
\hline$\alpha\left(\mathrm{h}^{-1}\right)$ & $0.00035^{\mathrm{a}}$ & $0.00035^{\mathrm{a}}$ & $0.00035^{\mathrm{a}}$ & $0.00035^{\mathrm{a}}$ \\
$T_{v}(\mathrm{~h})$ & 12 & $12^{\mathrm{c}}$ & $12^{\mathrm{c}}$ & $12^{\mathrm{c}}$ \\
$A_{g w}(\mathrm{ha})$ & $1.16^{\mathrm{b}}$ & 1.42 & & \\
$D_{T}\left(\mathrm{~mm} \mathrm{~h}^{-1}\right)$ & 3.4 & $3.4^{\mathrm{c}}$ & $3.4^{\mathrm{c}}$ & $3.4^{\mathrm{c}}$ \\
$S$ & & & 0.049 & $0.049^{\mathrm{d}}$ \\
$x / L$ & & & 0.0 & 0.87 \\
$d(\mathrm{~m}) \mathrm{amsl}^{\mathrm{e}}$ & & & 97.0 & 76.15 \\
\hline
\end{tabular}

a Pro-rated from the daily value in Table 1.

b The 1998 value from Table 1 (\#5).

c Copied from the 1998-1999 calibration.

d Same value as for deep well.

e amsl - above mean sea level.

the daily model (Fig. 4) provided hourly-based values of $T_{v}=12 \mathrm{~h}$ and $D_{T}=3.4 \mathrm{~mm} \mathrm{~h}^{-1}$ (Table 4). This same model was then calibrated to the 2004-2005 hourly data by fitting only the groundwater catchment area $A_{g w}$ (Fig. 5). Thus the model calibration procedure has maintained groundwater discharge dynamic behaviour from the daily model of 19962002 through to the hourly model of 2004-2005. The concurrent dynamic responses of piezometric level at the deep well (Fig. 6) and shallow well (Fig. 7) were provided by the piezometric model (Sect. 2.5), using the same hourly series of groundwater recharge and the same value of dynamic parameter $\alpha$ (Table 4).

The predicted hourly groundwater discharge shown in Figs. 4 and 5 still does not account satisfactorily for periods of higher flows with dynamics extending over periods of many days. These flows may also be part of the groundwater discharge regime but have not been captured by the dynamics of the simple groundwater model used for our analysis. The groundwater catchment area $A_{g w}=1.42$ ha (Table 4) calibrated for the 2004-2005 hourly data is greater than the value for the concurrent daily and hourly models for 1998 1999 (1.16 ha) or even the maximum value (1.32 ha) for the daily data (Table 2 ). We are not able to offer a convincing explanation for this difference.

Figure 6 shows reasonable prediction of the dynamics of piezometric levels in the deep well for the three highest events of the record, although the actual peaks are missing due to instrument failure. The two smaller events of November 2004 and January 2005 are poorly predicted, as is the timing of the initial rise in June 2004. We are not able to offer a convincing explanation for this observation other than the possibility that presence of very low-conductivity layers may have retarded vertical movement of groundwater.

The datum for the deep well model is $d=97.0 \mathrm{~m}$ (amsl) (Table 4), which represents the water level corresponding to

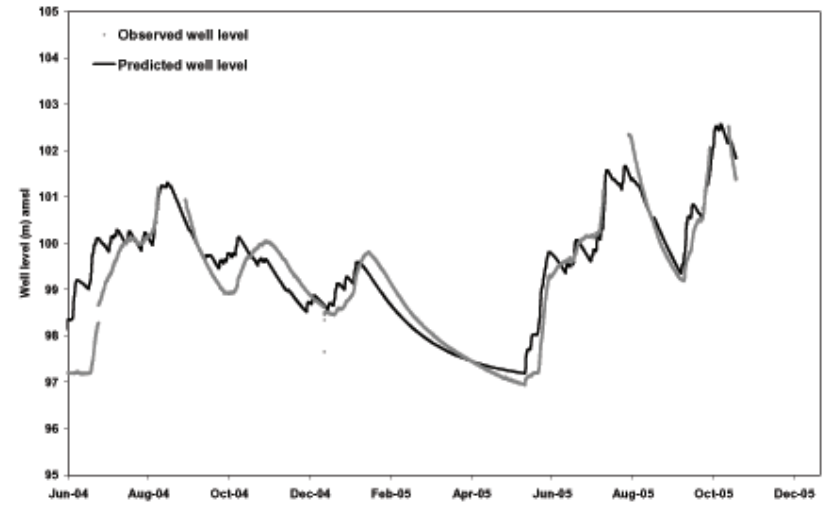

Fig. 6. Predicted hourly groundwater level for the deep well at Pukemanga.

long-term zero recharge. This level is significantly higher than the corresponding datum of $76.15 \mathrm{~m}$ (amsl) at the shallow well and the $\sim 73 \mathrm{~m}$ elevation of the wetland. The reason for this non-horizontal basis for the small groundwater catchment of the Pukemanga wetland is that this groundwater body is a local system within the regional groundwater body that is determined by the boundary conditions of the $430 \mathrm{~m}$ wide spur on which lies the Pukemanga Catchment (Fig. 1). At a time that the Pukemanga Stream might cease to flow because of continuing zero recharge, this local groundwater body would disappear and the regional groundwater would continue to drain to the streams that bound the spur. The resulting piezometric surface would then be expected to include the datum elevations of the deep well and shallow well. At this state of the groundwater body, drainage to the wetland is no longer available and the dynamics would be determined by the increased drainage paths to the bounding streams. The corresponding dynamic parameter $\alpha$ of the larger system is unlikely to have been detected in the analysis 


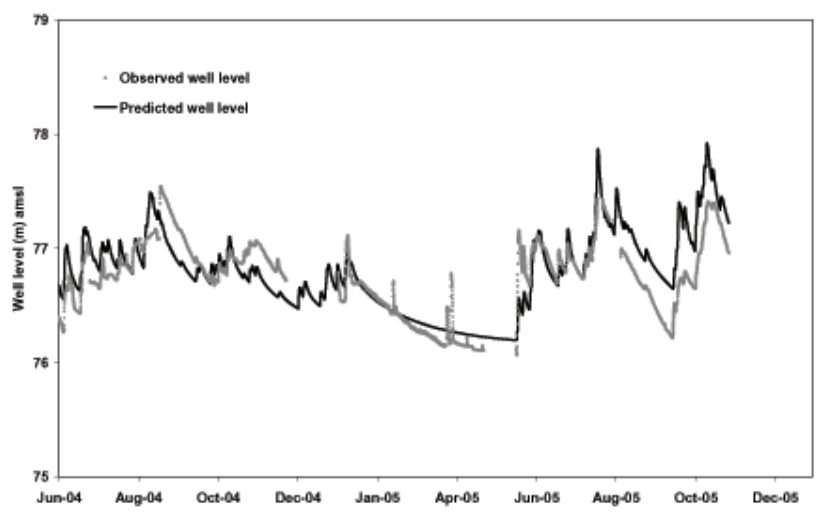

Fig. 7. Predicted hourly groundwater level for the shallow well WW4 at Pukemanga.

of the present data, and this underlying state has been parameterised in terms of spatially-varying $d$-values. It is likely that dynamic interaction between the local groundwater body contributing to Pukemanga Stream and the larger regional groundwater system is responsible for the time-varying size, and shape of the Pukemanga groundwater catchment.

Figure 7 shows that the piezometric response of the shallow well WW4 is reasonably predicted by the model, on the basis that the dynamic behaviour is part of the same groundwater body as involved in the piezometric level at the deep well and the groundwater discharge component of Pukemanga Stream.

\subsection{Aquifer hydraulic properties}

Table 5 has been calculated from Eq. (3) to enable consideration of feasible aquifer dimensions that are consistent with the calibrated dynamic behaviour, likely hydraulic conductivity, and drainable porosity of the vadose zone.

Table 4 shows the calibrated value of storativity $S$ is 0.049 . This value can be compared with the soil physical properties reported by Müller et al. (2006; Table 1). For depths to $120 \mathrm{~cm}$, the difference between field capacity and total pore volume is $0.01-0.08$, so it is not unexpected that in the weathered clay near the groundwater table the calibrated value of 0.049 is feasible. Table 5 shows values of hydraulic conductivity $K$, aquifer length $L$, and aquifer thickness $B$ that satisfy Eq. (3) for the calibrated values of $S=0.049$ and $\alpha=0.0085 \mathrm{~m} \mathrm{~d}^{-1}$.

Stewart et al. (2007) suggest a mean residence time of 614 years for the baseflow of Pukemanga Stream, based on tritium data. For average annual groundwater recharge of about $1 \mathrm{~m}$ (Table 2), and porosity of about 0.6 (Müller et al., 2006; Table 1, TPV), the aquifer thickness would be about $10-24 \mathrm{~m}$.

An estimate of aquifer length $L$ may be obtained from the horizontal distance between the Pukemanga weir and the deep well, and the scale ratio of $x / L=0.85$ (Table 4). The
Table 5. Hydraulic conductivity $K\left(\mathrm{~mm} \mathrm{~d}^{-1}\right)$ of the aquifer calculated from Eq. (3), for a range of aquifer dimensions, with dynamic parameter $\alpha=0.0085 \mathrm{~d}^{-1}$ and storativity $S=0.049$.

\begin{tabular}{ccccccc}
\hline \multirow{2}{*}{$B(\mathrm{~m})$} & \multicolumn{6}{c}{ Aquifer length $L(\mathrm{~m})$} \\
& 100 & 120 & 140 & 160 & 180 & 200 \\
\hline 5 & 833 & 1200 & 1633 & 2132 & 2699 & 3332 \\
10 & 417 & 600 & 816 & 1066 & 1349 & 1666 \\
20 & 208 & 300 & 408 & 533 & 675 & 833 \\
40 & 104 & 150 & 204 & 267 & 337 & 417 \\
60 & 69 & 100 & 136 & 178 & 225 & 278 \\
80 & 52 & 75 & 102 & 133 & 169 & 208 \\
\hline
\end{tabular}

resulting estimate is $L \sim 140 \mathrm{~m}$. Consideration of the results in Table 5 suggests that for aquifer thickness of about $20 \mathrm{~m}$, the required horizontal hydraulic conductivity would need to be about $400 \mathrm{~mm} / \mathrm{d}$. This value $\left(\sim 10^{-6} \mathrm{~m} \mathrm{~s}^{-1}\right)$ is within the typical range for sandstone (Freeze and Cherry, 1979; Table 2.2), and may be compared with the value of vertical conductivity required to support the partitioning threshold $D_{T}=3.4 \mathrm{~mm} \mathrm{~h}^{-1}$ (Table 4), which is $82 \mathrm{~mm} \mathrm{~d}^{-1}$. The consequent anisotropy of 5 for the ratio of horizontal to vertical conductivity is also feasible for sandstone (Freeze and Cherry, 1979; p.154).

In conducting this analysis we realise that this local aquifer system does not strictly satisfy the assumptions of the 1-D homogeneous model that is the basis of Eq. (3), which does not allow for convergence of flow in the horizontal plane, variation in transmissivity with changes in groundwater level, or interaction with a regional groundwater body. However, the results do indicate that relatively low conductivity material in a steep hillslope can support small groundwater bodies that have sufficient storage to maintain perennial headwater streams in this climate.

\subsection{Implications for nitrate discharge to surface waters}

Our original hypothesis was that groundwater is the dominant pathway for nitrate discharge from a catchment because the contributing water has all passed through the soil profile. Other pathways were considered to be minor. Table 3 shows that, on a unit area basis, $86 \%$ of streamflow from this land surface is groundwater discharge. For the Pukemanga Stream this proportion is about $70 \%$ because the groundwater catchment is less than half the topographical area. The remainder of the groundwater generated within the Pukemanga topographical catchment is most likely to drain into the Kiripaka Stream (Fig. 1). For assessing the effect of hill-country pastoral land use on nitrate discharge to streams, Pukemanga Catchment is not a representative sample of the larger spur of land on which it lies because of the disproportion of areas contributing to groundwater and near-surface flow paths. 
It is possible that groundwater may have been responsible for the formation of the small Pukemanga Catchment on the side of the much larger spur. The occurrence of the wetland suggests that groundwater sapping has been a significant geo-morphological process. This wetland, which is the source of Pukemanga Stream, provides an opportunity for some denitrification of groundwater discharge. The steep banks of the Kiripaka Stream, which receives the remaining groundwater dsicharge from the Pukemanga Catchment, do not support extensive riparian wetlands in this reach. Therefore, any investigation of likely zones of denitrification needs to take account of the proportions and locations of groundwater discharge from even a small research catchment such as Pukemanga.

\section{Conclusions}

The partial-area contribution of groundwater discharge to streamflow from the Pukemanga Catchment supports previous research (e.g., Verry, 2003) on the mismatch between groundwater catchments and the contributing topographical catchment of the associated stream. The results also support some degree of time-varying area of groundwater catchments (Winter et al., 2003). The differing catchment areas of groundwater discharge and near-surface runoff contribution to a stream mean that care is required in the hydrological analysis of the relative proportions of these contributions when conducting catchment-scale experiments. For the purpose of estimating nitrate contamination of streams from agricultural land use, robust estimates of groundwater discharge contribution are important because this is the primary transport route for nitrate leached from the soil profile. The quantification of nitrate transported in groundwater discharge is not the only issue. The land use practices that generate nitrate discharge may not all be in the topographical catchment of the stream of interest. Our study demonstrated this issue at a small headwater catchment scale but the lesson can also be applied at larger scales (Verry, 2003).

The groundwater contribution from the steep hillslopes of the Pukemanga catchment was a very high $(\sim 90 \%)$ proportion of the streamflow generation processes under a relatively wet rainfall climate. This particular proportion was supported by a requirement for vertical hydraulic conductivities within the vadose zone of no more than $4 \mathrm{~mm} \mathrm{~h}^{-1}$. It should be a consideration for other steep hill country catchments that the proportion of groundwater discharge in streamflow may be similarly high. The dynamics of groundwater discharge from this steep hillslope, which maintains a perennial stream, demonstrates that aquifer storage in headwater catchments can be an important component of water storage at the large catchment scale.

\section{Appendix A}

\section{Mathematical basis of the groundwater model}

The partial differential equation:

$$
\begin{aligned}
& \frac{\partial}{\partial x}\left[T_{x}(x, y) \frac{\partial h(x, y, t)}{\partial x}\right] \\
& +\frac{\partial}{\partial y}\left[T_{y}(x, y) \frac{\partial h(x, y, t)}{\partial y}\right]+P(x, y) R(t) \\
& =S(x, y) \frac{\partial h(x, y, t)}{\partial t}
\end{aligned}
$$

describes the piezometric response $h(x, y, t)$ of $2 \mathrm{D}$ horizontal, transient groundwater flow in a heterogeneous, anisotropic aquifer, to recharge of fixed spatial pattern $P(x, y)$ with time-varying magnitude $R(t)$. The aquifer properties of transmissivity components $T_{x}, T_{y}$ and storativity $S$ are assumed to be time-invariant. It is shown (Sahuquillo, 1983; Sloan, 2000; Pulido-Velazquez et al., 2005) that the solution to Eq. (A1) can be expressed in terms of the eigenvalues and eigenfunctions of this distributed linear system. Pulido-Velazquez et al. (2006) also show that time-varying transmissivity in unconfined aquifers can be incorporated by means of a modification to the recharge stress term.

The eigenvalue solution can be considered as a parallel set of conceptual first-order, linear water storages. The contribution of the $i$ th storage to the output value $y(t)$ of piezometric head or groundwater discharge at specific locations is:

$$
\begin{aligned}
& y_{i}(t)=\exp \left(-\alpha_{i} t\right) y_{i}(0)+\beta_{i}\left[1-\exp \left(-\alpha_{i} t\right)\right] R \\
& y(t)=\sum_{i=0}^{\infty} y_{i}(t)
\end{aligned}
$$

in response to a recharge stress $R(t)=R$ for the time interval $(0, t)$. The parameters $\alpha_{i}$ are the eigenvalues of the system and remain the same for all recharge patterns and output variables. The parameters $\beta_{i}$ depend on whether $y(t)$ represents piezometric head or groundwater discharge, the spatial pattern $R(x, y)$ of recharge, and the spatial location of the output of interest.

Theoretically, there are an infinite number of eigenvalues in the solution but in practice many of these make an insignificant contribution. Pulido-Velazquez et al. (2005) provide measures of error for levels of truncation of terms in particular applications. When the number of eigenvalues is truncated to $n$ terms, conservation of mass is assured by setting the $n^{\text {th }}$ term $\beta_{n}$ as:

$\beta_{n}=\sum_{i=1}^{\infty} \beta_{i}-\sum_{i=1}^{n-1} \beta_{i}$

In the case of numerical groundwater models, the parameters $\alpha_{i}, \beta_{i}(i=1, n)$ can be computed from the computational matrix for the $n$ nodes or cells. For particular applications, the number of eigenvalues can be truncated to 
a smaller set that enables more rapid model execution for use in complex water resource systems analysis (Andreu and Sahuquillo, 1987).

Analytical expressions for eigenvalues and eigenfunction coefficients can be derived for some simple aquifer models and these provide useful dynamic models of groundwater discharge, piezometric response (Sloan, 2000), and stream-aquifer interaction (Pulido-Velazquez et al., 2005). The eigenvalues for the aquifer component shown in Fig. 2, with discharge to a fully-penetrating stream are:

$\alpha_{i}=\left[\frac{(2 i-1) \pi}{2}\right]^{2} \alpha$

$\alpha=\frac{K B}{S L^{2}}$

The eigenfunction coefficients for groundwater discharge to the stream are:

$\beta_{i}=\frac{8}{[(2 i-1) \pi]^{2}}$

and for the piezometric head $h(x, t)$ the coefficients are:

$\beta_{i}=\frac{c_{i} F_{i}(x)}{\alpha_{i}}$

$c_{i}=\frac{4(-1)^{i+1}}{(2 i-1) \pi}$

$F_{i}(x)=\frac{1}{S} \cos \left[\frac{(2 i-1) \pi x}{2 L}\right]$

Pulido-Velazquez et al. (2005) show that when the stream is partially connected the eigenvalues are modified to reflect the streambed resistance and the first eigenfunction coefficient increases towards unity. In the present paper we use the fullyconnected form described by Eqs. (A4)-(A6).

For implementation of the model at time intervals of $\Delta t$, Eq. (A2) become a set of difference equations:

$$
\begin{aligned}
& y_{i}(k)=a_{i} y_{i}(k-1)+b_{i} R(k) \\
& a_{i}=\exp \left(-\alpha_{i} \Delta t\right) \\
& b_{i}=\beta_{i}\left[1-\exp \left(-\alpha_{i} \Delta t\right)\right] \\
& y(k)=\sum_{i=0}^{n} y_{i}(k)
\end{aligned}
$$

The input recharge $R(k)$ is assumed to have a constant value during the time interval $\Delta t$. However, in the model structure shown in Fig. 2 recharge to the aquifer component is the output from the first-order model of transport through the vadose zone. If the vadose zone has a mean hydrometric residence time of $T_{v}$ then the recharge $R(k)$ to the groundwater surface from soil-water drainage $D_{g w}(k)$ at time intervals of $\Delta t$ is:

$$
\begin{aligned}
& R(k)=a_{v} R(k-1)+b_{v} D_{g w}(k) \\
& a_{v}=\exp \left(-\frac{1}{T_{v}}\right) \\
& b_{v}=\left[1-\exp \left(-\frac{1}{T_{v}}\right)\right]
\end{aligned}
$$

The vadose zone component is in series with the parallel set of Eq. (A7). The resulting difference equations can be developed by means of z-transforms (e.g., Bidwell, 2005), so that:

$$
\begin{aligned}
y_{i}(k) & =\left(a_{i}+a_{v}\right) y_{i}(k-1)-a_{i} a_{v} y_{i}(k-2) \\
& +b_{i} b_{v} D_{g w}(k) \\
y(k) & =\sum_{i=0}^{n} y_{i}(k)
\end{aligned}
$$

Acknowledgements. The technical assistance of Craig Burgess, Markus Haas, Olaf Andler, and Aaron Wall at the field site is gratefully acknowledged. We also thank Sandy Elliott and coworkers from NIWA Hamilton for providing rainfall, streamflow, and terrain data.

Edited by: N. Romano

\section{References}

Adams R., Parkin, G., Rutherford, J. C., Ibbitt, R. P., and Elliott, A. H.: Using a rainfall simulator and a physically based hydrological model to investigate runoff processes in a hillslope, Hydrol. Process., 19, 2209-2223, 2005.

Adams, R. and Elliott, S.: Physically based modelling of sediment generation and transport under a large rainfall simulator, Hydrol. Process., 20, 2253-2270, 2006.

Allen, R. G., Pereira, L. S., Raes, D., and Smith, M.: Crop evapotranspiration (guidelines for computing crop water requirements), FAO Irrigation and Drainage Paper No. 56, 1988.

Andreu, J. and Sahuquillo, A.: Efficient aquifer simulation in complex systems, J. Water Res. Pl.-ASCE, 113, 110-129, 1987.

Bidwell V. J.: Realistic forecasting of groundwater level, based on the eigenstructure of aquifer dynamics, Math. Comput. Simulat., 69, 12-20, 2005.

Bruce, J. G.: Soils of part Raglan County, South Auckland, New Zealand, New Zealand Soil Bureau Bulletin 41. 1978.

Freeze, R. A. and Cherry, J. A.: Groundwater. Prentice Hall, Upper Saddle River, NJ., 1979.

Furey, P. R. and Gupta, V. K.: A physically based filter for separating base flow from streamflow time series, Water Resour. Res., 37, 2709-2722, 2001.

Hewitt, A. E.: New Zealand Soil Classification, Landcare Research Science Series No. 1, 1998.

Huyck, A. A. O., Pauwels, V. R. N., and Verhoest, N. E. C.: A base flow separation algorithm based on the linearized Boussinesq equation for complex hillslopes, Water Resour. Res., 41, WO8415, doi:10.1029/2004WR003789, 2005.

Kear, D. and Schofield, J. C.: Geology of the Ngaruawahia Subdivision, New Zealand Geological Survey Bulletin 88, 1978.

Minhas, B. S., Parikh, K. S., and Srinivasan, T. N.: Toward the production function for wheat yields with dated inputs of irrigation water, Water Resour. Res., 10, 383-393, 1974.

Müller, K., Stenger, R., and Rahman, A.: Herbicide loss in surface runoff from a pastoral hillslope in the Pukemanga catchment (New Zealand): Role of pre-event soil water content, Agr. Ecosyst. Environ., 112, 381-390, 2006. 
Pulido-Velazquez, M. A., Sahuquillo-Herraiz, A., Ochoa-Rivera, J. C., and Pulido-Velazquez, D.: Modeling of stream-aquifer interaction: the embedded multireservoir model, J. Hydrol., 313, 166-181, 2005.

Pulido-Velazquez, D., Sahuquillo, A., and Andreu J.: A two-step explicit solution of the Boussinesq equation for efficient simulation of unconfined aquifers in conjunctive-use models, Water Resour. Res., 42, WO5423, doi:10.1029/2005WR004473, 2006.

Quinn, J. M., Cooper, A. B., Davies-Colley, R. J., Rutherford, J. C., and Williamson, R. B.: Land use effects on habitat, water quality, periphyton, and benthic invertebrates in Waikato, New Zealand, hill-country streams, New Zeal. J. Mar. Fresh., 31, 579597, 1997.

Quinn, J. M. and Stroud, M. J.: Water quality and sediment and nutrient export from New Zealand hill-land catchments of contrasting land use, New Zeal. J. Mar. Fresh., 36, 409-429, 2002.

Sahuquillo, A.: An eigenvalue numerical technique for solving unsteady linear groundwater models continuously in time, Water Resour. Res., 19, 87-93, 1983.
Sloan, W. T.: A physics-based function for modeling transient groundwater discharge at the watershed scale, Water Resour. Res., 36, 225-241, 2000.

Smith, C. M., Wilcock, R. J., Vant, W. N., Smith, D. G., and Cooper, A. B.: Towards sustainable agriculture: freshwater quality in New Zealand and the influence of agriculture, MAF Policy Technical Paper, 93/10. 208 p., ISSN 171-4662, 1993.

Stewart, M. K., Mehlhorn, J., and Elliott, S.: Hydrometric and natural tracer (oxygen-18, silica, tritium and sulphur hexafluoride) evidence for a dominant groundwater contribution to Pukemanga Stream, New Zealand, Hydrol. Process., 21, 3340-3356, doi:10.1002/hyp6557, 2007.

Verry, E. S.: Estimating ground water yields in small research basins, Ground Water, 41-Watershed Issue, 1001-1004, 2003.

Winter, T. C., Rosenberry, D. O., and LaBaugh, J. W.: Where does the ground water in small watersheds come from?, Ground Water, 41-Watershed Issue, 989-1000, 2003. 